\title{
Analysis of the Electric Power Potential as Illustrated by the Ues of Russia
}

\author{
V.V. Trufanov, P.S. Drachev, V.V. Khanaev*
}

Melentiev Energy Systems Institute of Siberian Branch of Russian Academy of Sciences, Irkutsk, Russia

\begin{abstract}
The paper presents an analysis of the current state of the Unified Energy System (UES) of Russia, which aims to identify "weak points," regional shortage and excess energy systems, locations of the electricity consumption growth, and seeks to determine the technical potential of the power grid for electricity transmission. This analysis relies on the models developed for optimization in terms of the maximum excess capacity for the entire Unified Energy System of Russia and for individual regions of the country in the context of the existing mix of generating capacity and cross-regional structure of the power grid. Calculations were made for the conditions corresponding to the reported performance of the Unified Energy System of Russia in 2020. The cross-regional power grid of the Unified Energy System of Russia is capable of covering the capacity needs of all the country's power systems, and almost everywhere has a significant available transfer capability of power transmission lines.
\end{abstract}

Index Terms: Unified Energy System of Russia, region, generation, power grid, analysis, model, excess capacity, potential, bottlenecks.

\section{INTRODUCTION}

One of the significant stages in formulating the strategies for the development of electric power systems [1-3] is an analysis of their existing state. In the process of this analysis, it is necessary to identify «bottlenecks» in the system, the power systems with a capacity shortage or excess, the technical potential of the power grid for power transmission, possible locations of power consumption growth, and others [4-7]. The results of this

\footnotetext{
${ }^{*}$ Corresponding author.

E-mail: venven@list.ru
}

http://dx.doi.org/10.38028/esr.2021.03.0002

Received September 26, 2021. Revised October 11, 2021.

Accepted October 31, 2021. Available online November 28, 2021.

This is an open access article under a Creative Commons Attribution-NonCommercial 4.0 International License.

(C) 2021 ESI SB RAS and authors. All rights reserved. analysis are employed to form alternatives for levels and territorial distribution of power consumption, options for construction of power plants, and power grid expansion. This information is also needed to assess the energy security of the country's regions [8].

The importance of quantitative analysis of the potential of the existing electric power industry in Russia is also determined by the current situation, i.e., the presence of significant excess generating capacity in the country.

The assessment of the technological potential of the existing power grid depends on the electricity transmission capability to cover additional demand for electricity at grid nodes, whereas generating capacity potential is determined by the relationship between the capacity demand and the available capacity of power plants in the regions of the country.

Let us consider the problem of determining the maximum possible electricity consumption in the power systems across the country, without expansion of grid and generating capacity (problem 1).

Problem statement: find the maximum total excess capacity (or maximum generation) in the system

$$
\max \sum_{i}\left(g_{i}-s_{i}\right), i \in I \text {, }
$$

where $g_{i}$ is the load coverage at the node $i$ :

$$
g_{i}=p_{i}+\sum_{k} t_{k i}\left(1-d_{k i}\right)-\sum_{k} t_{i k}, i, k \in I,
$$

provided that the electricity demand of all nodes is covered

$$
g_{i} \geq s_{i}, i \in I,
$$

at the given maximum generation at the nodes

$$
0 \leq p_{i} \leq P_{i}, i \in I \text {, }
$$

and constraints on power flows

$$
0 \leq t_{i k} \leq T_{i k}, i, k \in I \text {. }
$$

The optimized variables $p_{i}, g_{i}, t_{i k}$ (power plant load, load coverage, and power flow from node $i$ to node $k$ ) are non-negative here, $I$ is a set of power system nodes.

The given variables are $s_{i}$ - existing consumption at nodes, $P_{i}-$ limit load of operating power plants at nodes, $T_{i k}$ - transfer capability of existing transmission lines, $d_{i k}$ - specific power losses during transmission from node $i$ to node $k$.

The obtained values of excess power determine the 


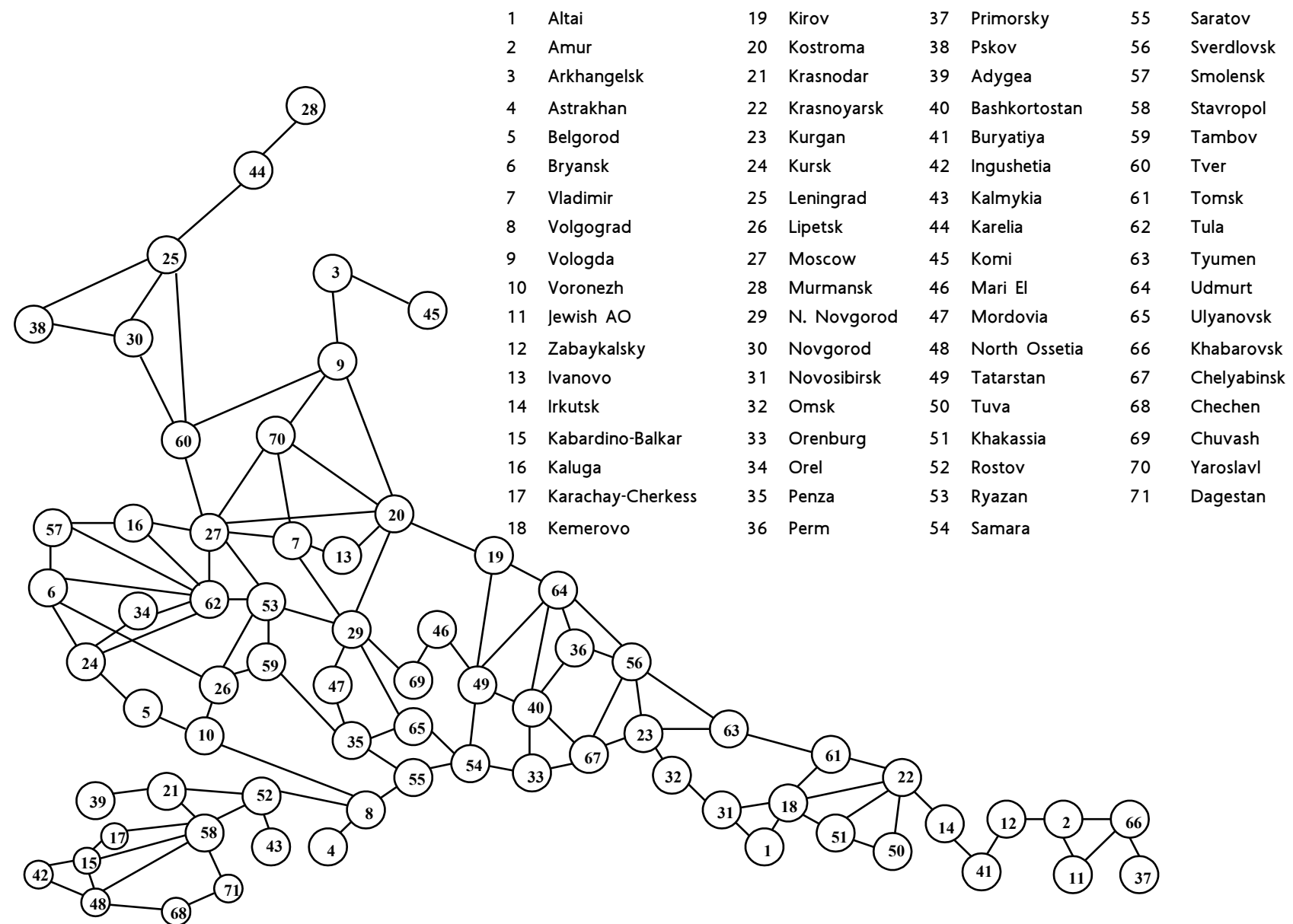

Fig. 1. Equivalent circuit of the UES of Russia

locations of possible growth of consumer loads in the system without reinforcing the grid and power plant capacity additions. Transmission lines where power flows were at the limit of transfer capability form a set of loaded grid elements, i.e., possible candidates for expansion.

Under normal (shortage-free) conditions, maximum total surplus power will be achieved with minimum losses in the grid, i.e., these criteria are identical.

Mathematical models similar in their statements to the above are used to minimize power shortages in the process of analyzing the adequacy of power systems [9-16].

The optimization criterion (1) in the considered model assumes equal importance of possible load growth at all system nodes. If it is necessary to single out certain regions because of their particular importance (for example, those of the Russian Far East), appropriate weighting coefficients can be introduced into criterion (1).

Apart from this statement (placing new consumers to maximize the total consumption in the system, given the capabilities of the existing generation and power grid with minimal energy construction), there can also be another statement. Namely, it is necessary to maximize consumption at a single system node, considering the grid capabilities. In this case, the losses in the grid will naturally be higher than in the first problem. The statement of this problem is as follows. Determine the maximum excess capacity at a single $i$-th node (problem 2 ):

$\max \left(g_{i}-s_{i}\right),(6)$

subject to constraints (2)-(5). This problem is solved for all nodes of the power system equivalent circuit.

\section{PRACTICAL APPLICATION}

The above problem statements were applied in the corresponding analysis of the Unified Energy System (UES) of Russia. An equivalent circuit of UES was built for the calculations (Fig. 1).

The circuit includes 71 nodes, each corresponding to a power system of a constituent entity of the Russian Federation, and cross-system (cross-regional) power lines connecting them (with a voltage of $220 \mathrm{kV}$ and above). We considered the state of the UES for the year 2020.

Background information on generation and transmission lines is taken from the Scheme and Program for the Development of the Unified Energy System of Russia in 2020-2026 [Order of the Ministry of Energy of the Russian Federation No. 508 of June 30, 2020]. The reported load plus a $20 \%$ capacity reserve, the same for all nodes, is taken as the node load $s_{i}$. The limit load of power plants $P_{i}$ was assumed to be equal to the reported available capacity at the nodes of the equivalent circuit. The transfer 


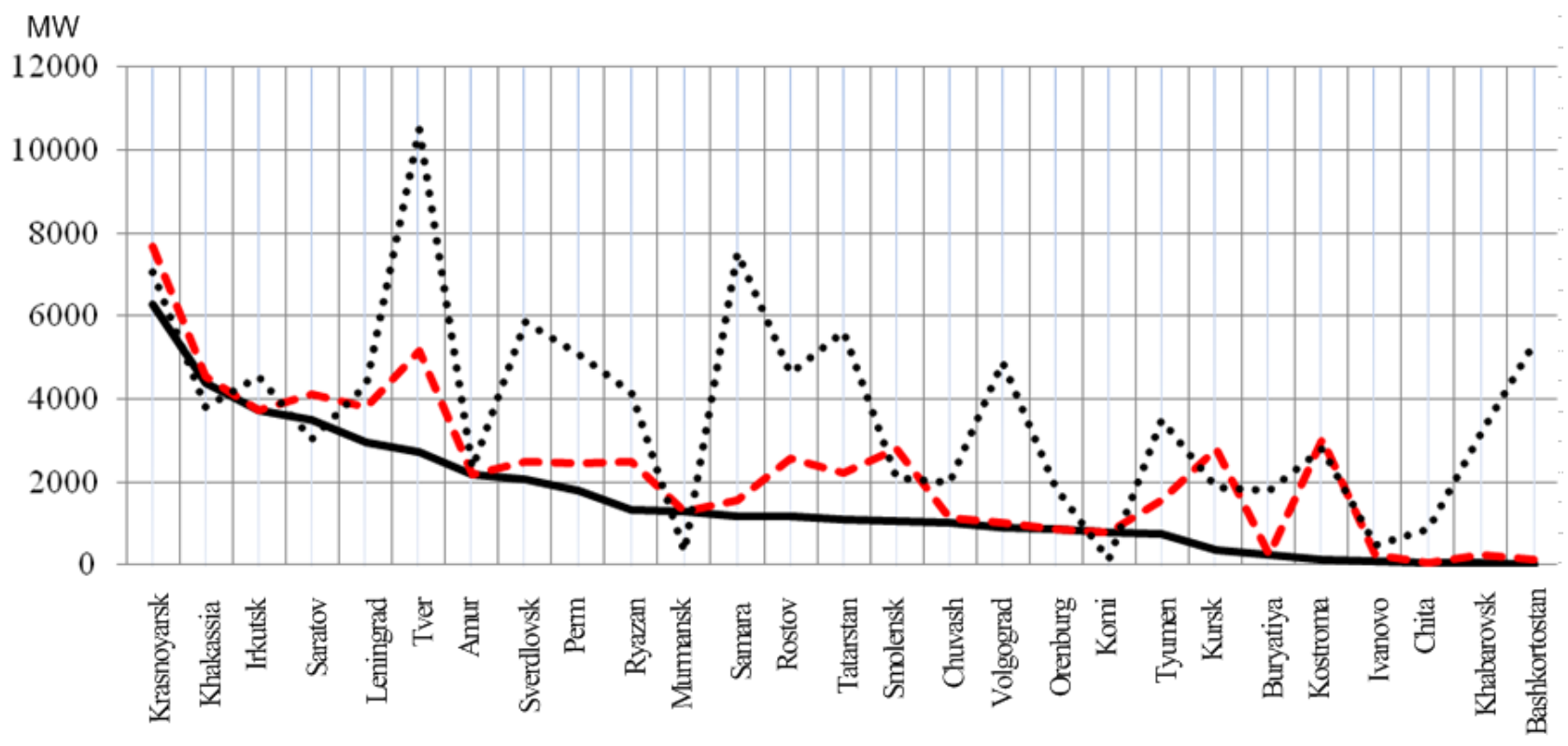

Node excess $\quad-0-$ Initial excess

..... Power transmission lines with available transfer capability

Fig. 2. Excess capacity of Russian power systems (MW), given maximum total excess of the UES of Russia.

capability of transmission lines $T_{i k}$ is assumed to be equal to the natural power of the lines of corresponding voltages, reduced by $20 \%$ to ensure static stability. The value of specific power losses during power transmission is assumed to be $6 \%$ per $1000 \mathrm{~km}$, which is the same for all types of transmission lines.

The main results of the model 1 (1)-(5) calculations for the maximum total excess of Russia's power systems are shown in Fig. 2. Only power systems with positive values of calculated excess capacity are shown. The rest of them have zero excess. We provide the values of calculated and initial excess capacity and transfer capability of transmission lines incoming to the power systems and the remaining available transfer capability for power flows.

The total generating capacity of Russian power systems assumed in the calculation was $234.8 \mathrm{GW}$, the overall load of consumers was $192.5 \mathrm{GW}$, their difference or initial excess capacity was $42.3 \mathrm{GW}$.

Calculated total excess capacity of all Russian power systems was $42.0 \mathrm{GW}$ or $18 \%$ of the total generating capacity. This is $0.3 \mathrm{GW}$ less than the total initial excess due to the need to cover a load of power systems with an initial capacity shortage and the corresponding power losses in cross-regional power tie lines.

Table 1 shows the regional power systems with the highest values of calculated excess capacity (the top ten of them).
The power system of the Krasnoyarsk Territory has the maximum calculated excess capacity $(6.3 \mathrm{GW})$. The power systems shown in this Table are the prime candidates for possible load growth without generating capacity additions and with the minimal expansion of the power grid. The total capacity of these ten nodes is $31.0 \mathrm{GW}$, which accounts for most $(74 \%)$ of the excess of all power systems of the UES of Russia.

The structure of these systems and the systems with the highest excess capacity partially overlap; the first six systems are on both lists, i.e., a large calculated excess capacity is determined by the presence of a significant initial excess. There was a positive initial excess in 33 systems (out of 71). The remaining 38 systems initially had a shortage of capacity. The calculated positive excess was found in 27 systems, each with a positive initial surplus. The calculated excess in the remaining 44 systems was zero. In all systems with the positive calculated excess, its value was less than the initial excess, and after some surplus power was supplied to adjacent nodes, there was an available transfer capability of the connected power lines for almost all excess nodes.

Fig.3. shows in an aggregated way the power flows formed to cover a load of the systems initially experiencing a capacity shortage.

The left-hand side of the Figure shows systems that

Table 1. Excess capacity (GW) at the first ten nodes with the highest excess.

\begin{tabular}{ccccccccccc}
\hline \hline Krasnoyarsk & Khakassia & Irkutsk & Saratov & Leningrad & Tver & Amur & Sverdlovsk & Perm & Ryazan & $\begin{array}{c}\text { UES of the } \\
\text { Russian } \\
\text { Federation }\end{array}$ \\
\hline \hline 6.3 & 4.4 & 3.7 & 3.5 & 3.0 & 2.7 & 2.2 & 2.1 & 1.8 & 1.3 & $\mathbf{3 1 . 0}$ \\
\hline \hline
\end{tabular}


MW

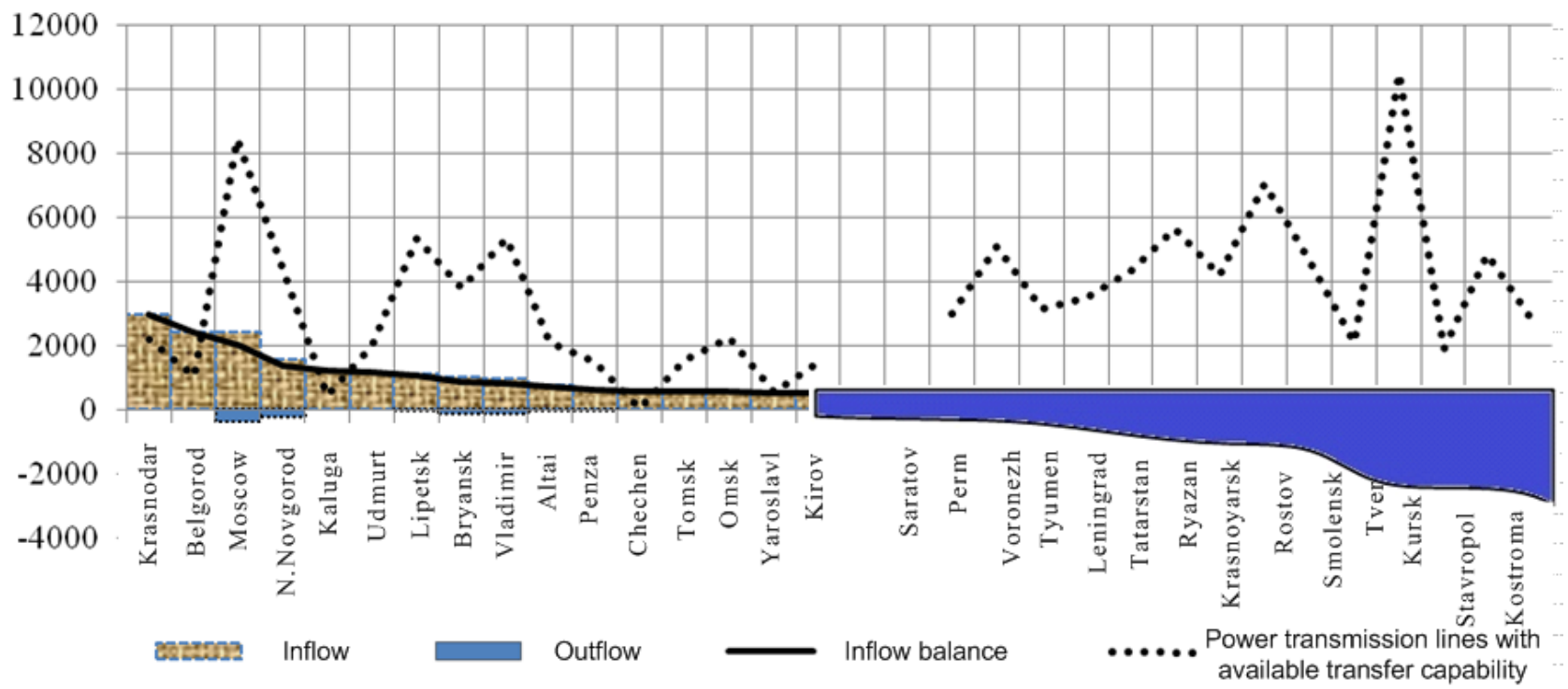

Fig. 3. Cross-system power flows (MW).

MW

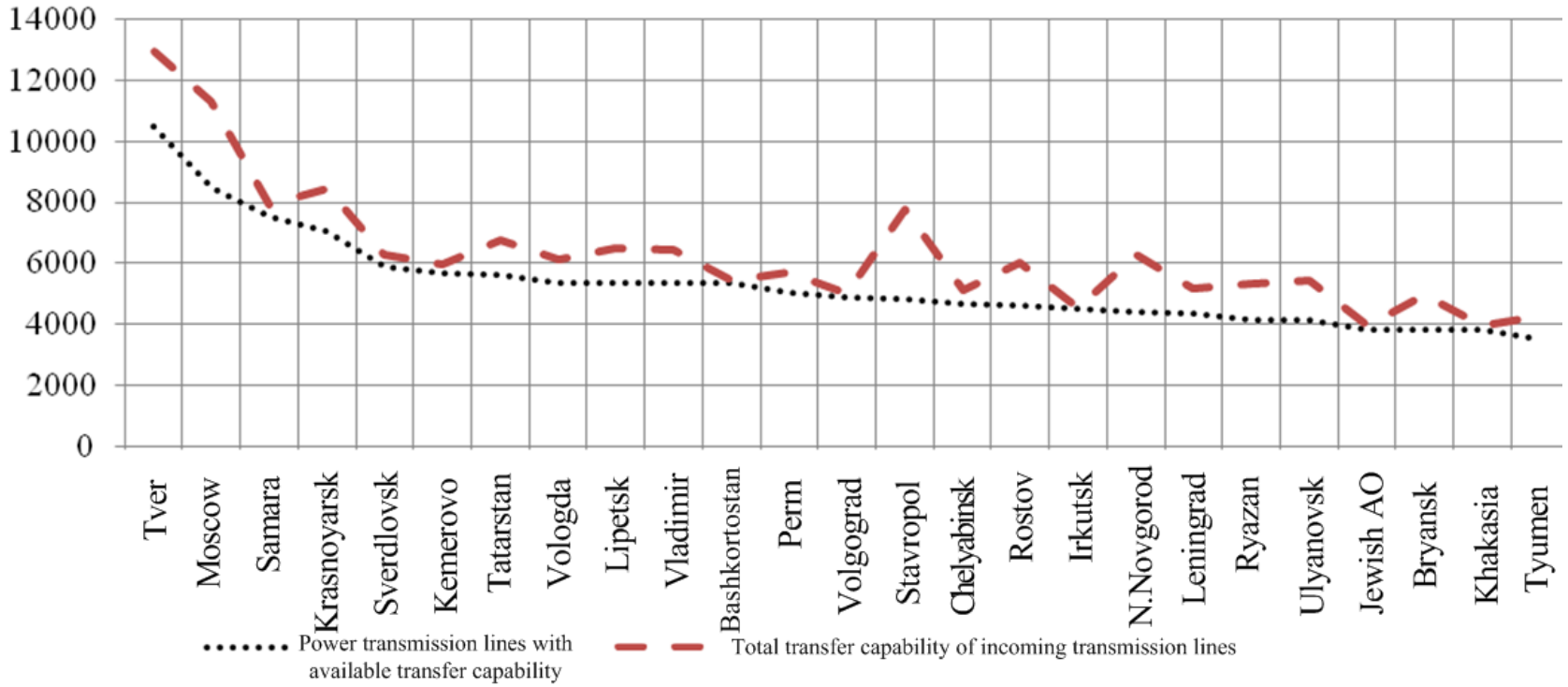

Fig. 4. Transfer capability of incoming transmission lines (MW).

initially have a power shortage and receive flows from the outside. The right-hand side shows redundant systems. The systems with relatively small flows in the center are not indicated in the Figure. As seen in the Figure, systems receiving the greatest power inflow are those of the Krasnodar Territory, the Belgorod Region, and Moscow Region; and the systems of the Kostroma Region, Stavropol Territory, and the Kursk Region show the greatest output. At the same time, almost all systems have the available transfer capability of their incoming power lines.

The value of the available transfer capability of the transmission lines incoming to regional systems, as shown in Fig. 4, is used to identify the power systems that are most suitable for placing generating capacity with subsequent power output to neighboring systems without significant expansion of the power grid. These are the systems of the Tver Region, Moscow Region, Samara Region, Krasnoyarsk Territory, and others.

To determine the power systems with the lowest cost of connecting new consumers, we performed a series of calculations with the criterion of maximum excess values of individual systems (model 2). The results of these calculations are shown in Fig. 5.

We give the values of excess power during local optimization of regional power systems, their values during optimization of the total excess in Russia (based on the previous calculation), and the difference between these values, i.e., an increase in excess capacity. 


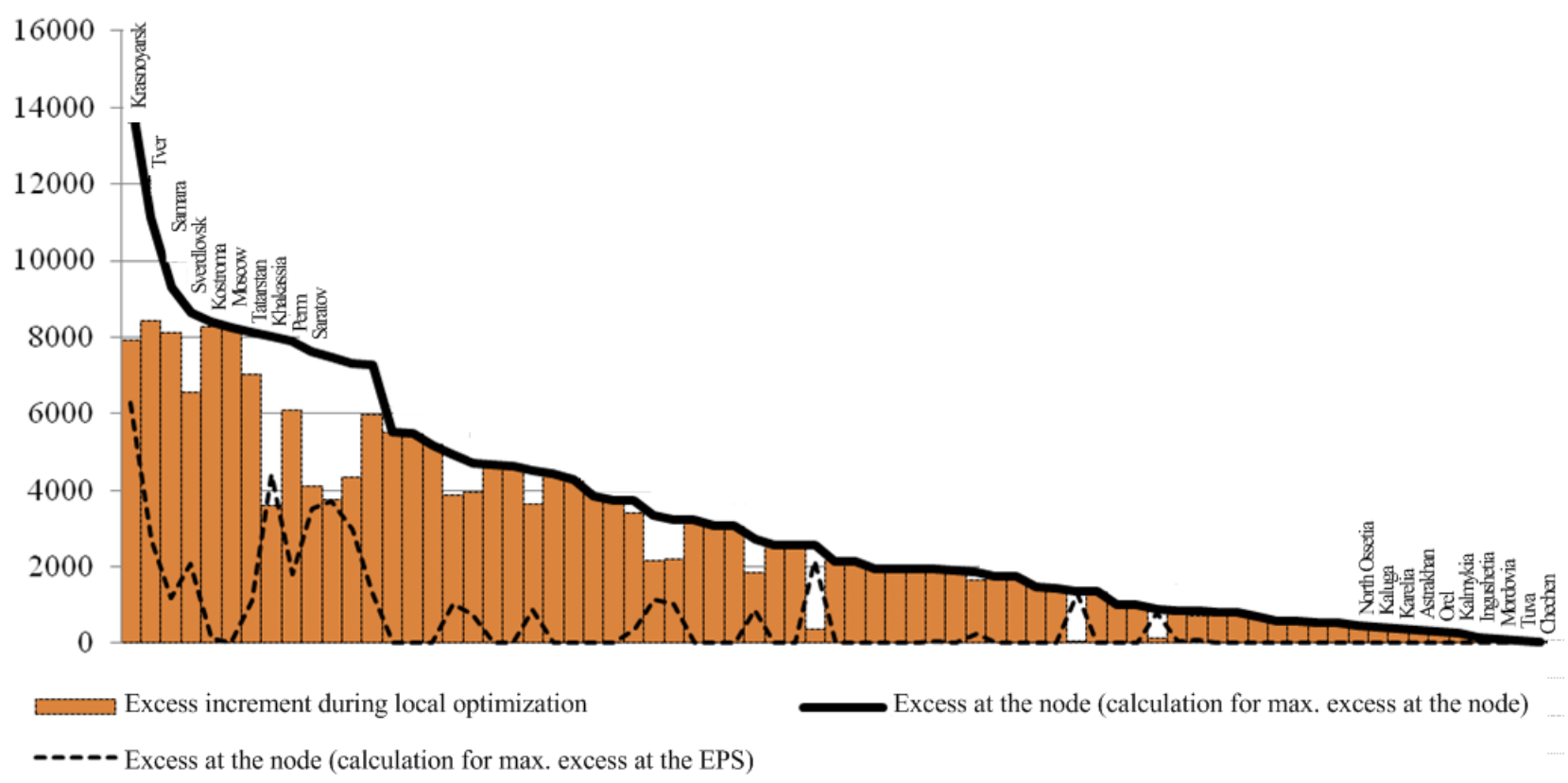

Fig. 5. Results of local optimization of excess capacity of regional systems (MW).

This Figure indicates that there is maximum excess capacity in the systems of Krasnoyarsk Territory, the Tver Region, Samara Region, Sverdlovsk Region, and others. The top ten of these power systems coincide with the list of the top systems identified according to the global optimization results only partially (6 out of 10) (see Fig. 2). Changes in this list are determined by the transfer capabilities of the power lines incoming to these nodes.

The largest values of the growth in local excess capacity relative to excess capacity in the case of global optimization are in the systems (the Tver Region, Moscow Region, Kostroma Region, and others) with maximum power output and the highest available transfer capability of the connected lines shown in Figures 3 and 4.

\section{CONCLUSION}

1. We have proposed a methodology for assessing the energy potential of Russian regions using mathematical models for calculating the excess capacity of power systems.

2. Under the assumed initial conditions, there is a significant excess capacity of about $42 \mathrm{GW}$ or $18 \%$ of the total available capacity of power plants in the existing Unified Energy System of the country as of the end of 2020.

3. The calculations have revealed the regions with the highest energy potential. These are the Krasnoyarsk Territory, Tver Region, Samara Region, Sverdlovsk Region, Kostroma Region, and Moscow Region. The total potential of the ten nodes being the best in terms of this characteristic is high and amounts to about $75 \%$ of the overall potential of Russia's power systems.

4. The least potential is available in the Chechen Republic, Mordovia, Ingushetia, Kalmykia, Orel Region, Astrakhan Region, and others.
5. The cross-regional power grid of the UES of Russia can cover the power needs of all the country's power systems, and almost everywhere has significant available transfer capabilities of power transmission lines.

\section{REFERENCES}

[1] N. I. Voropai, S. V. Podkovalnikov, V. V. Trufanov, et al., Expansion planning of electric power systems: Methodology, models, methods, and their application, N. I. Voropai, Ed. Novosibirsk, Russia: Nauka, 2015, 448 p. (in Russian)

[2] V. V. Trufanov, "Modeling the expansion of the backbone power grid in the market environment," Proceedings of Irkutsk State Technical University, no. 3, pp. 117-122, 2013. (in Russian)

[3] P. S. Drachev, "Market model for the expansion of the backbone power grid," Proceedings of Irkutsk State Technical University, no. 1, pp. 125-134, 2013. (in Russian)

[4] N. Mazzi, B. Zhang, D. S. Kirschen, "An Online Optimization Algorithm for Alleviating Contingencies in Transmission Networks," IEEE TPWRS, vol. 33, no. 5, pp. 5572-5582, Sep. 2018, DOI: 10.1109/TPWRS.2018.2808456.

[5] P. Falugi, I. Konstantelos, G. Strbac, "Planning with multiple transmission and storage investment options under uncertainty: A nested decomposition approach," IEEE TPWRS, vol. 33, no. 4, pp. 3559-3572, July 2018. DOI: 10.1109/ TPWRS.2017.2774367.

[6] S. Dehghan, N. Amjady, A. J. Conejo, "Adaptive Robust Transmission Expansion Planning Using Linear Decision Rules," IEEE TPWRS, vol. 32, no. 5, pp. 4024-4034, Sept. 2017. DOI: 10.1109/ TPWRS.2017.2652618. 
[7] E. Karimi, A. Ebrahimi, "Inclusion of Blackouts Risk in Probabilistic Transmission Expansion Planning by a Multi-Objective Framework," IEEE TPWRS, vol. 30, no. 5, pp. 2810-2817, Sept. 2015. DOI: 10.1109/ TPWRS.2014.2370065.

[8] Security of Russia. Its legal, socio-economic, and scientific-and-engineering aspects. Energy security. (Issues of operation and expansion of the electric power industry). Moscow, Russia: MGF Znanie, 2001, 480 p. (in Russian)

[9] Yu. Ya. Chukreev, Models for ensuring the reliability of electric power systems. Syktyvkar, Russia: Komi Scientific Centre UB RAS, 1995, 176 p. (in Russian)

[10] G. F. Kovalev, N. I. Voropai, Factoring in of reliability for the assessment of system effects in the electric power industry. Novosibirsk, Russia: Nauka, 2018, 217 p. (in Russian)

[11] N. I. Voropai, V. V. Trufanov, "Mathematical modeling of electric power systems development in the current context," Elektrichestvo, no. 10, pp. 6-13, 2000. (in Russian)

[12] Energy systems studies: The Siberian Energy Institute. Energy Systems Institute schools of thought in hindsight, N. I. Voropai, Ed. Novosibirsk, Russia: Nauka, 2010, 686 p. (in Russian)

[13] N. I. Voropai, Z. A. Styczynski, I. N. Shushpanov, Pham Chung Son, K. V. Suslov, "A model of security of «active» electric distribution grids," Proceedings of the Russian Academy of Sciences. Power Engineering, no. 6, pp. 70-79, 2013. (in Russian)

[14] N. I. Voropai, "Hierarchical modeling for expansion planning of electric power systems," Exponenta Pro. Matematika v prilozheniyakh, no. 4. pp.24-27, 2003. (in Russian)

[15] Energy security of Russia. Novosibirsk, Russia: Nauka, 1998, 302 p. (in Russian)

[16] G. F. Kovalev, V. V. Trufanov, G. A. Fedotova, et al. "A software package for EPS expansion planning and reliability research," in Methods for control of physical and engineering energy systems in the new context. Novosibirsk, Russia: Nauka, 1995, pp. 298302. (in Russian)

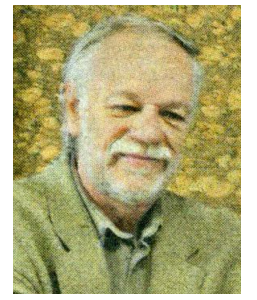

Trufanov Viktor Vasilievich graduated from the Irkutsk Polytechnic Institute (ISTU) in 1970. In 2015 he received the degree of Doctor Techn. Sci. from Melentiev Energy Systems Institute of Siberian Branch of the Russian Academy of Sciences (ESI SB RAS). His research interests are in the field of problems of prospective forecasting of electric power systems.

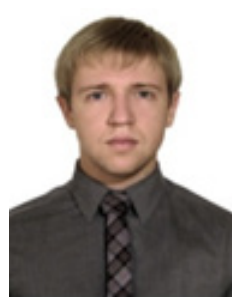

Pavel Drachev was born in Irkutsk, Russia. He graduated from Irkutsk State Technical University in 2009, received a Ph.D. degree in Power Engineering in 2017. Currently, he is a researcher at ESI SB RAS, Irkutsk, Russia. His research interests include transmission system expansion.

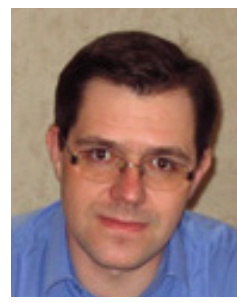

Veniamin Khanayev graduated from the Power Engineering Faculty of Irkutsk State Technical University (ISTU) in 1996 with a degree in power engineering. In 2008, he received his Ph.D. degree in power engineering from ESI SB RAS. Currently, he is a lead engineer at ESI SB RAS. His research interests are optimization of power system expansion and efficiency of electrical load control. 